See Article page 197.

\section{Commentary: Fashioning a replacement}

\section{J. W. Awori Hayanga, MD, MPH, FACS, FRCS, FCCP}

As the volume of cardiac surgery increases unabated, the number of reoperative procedures follows suit. The increasing incidence of end-stage cardiac disease is becoming increasingly matched by a growing occurrences of hostile mediastinum, concomitant histories of previous irradiation, and porcelain vasculature, each of which further precludes safe entry into the chest. As a result, there is growing interest in nonsternotomy options to provide indirect access to the left ventricle. These options include the supraceliac aorta, innominate artery, and the left axillary artery. ${ }^{1}$ Tucker and colleagues ${ }^{2}$ report the novel use of an extra-anatomic bypass to augment left ventricular assist device flow. ${ }^{2}$ They fashioned an augmentation graft to improve axillary artery outflow with the use of a left axillary to right axillary arterial bypass graft.

The authors achieved this by siting the anastomosis on the left axillary artery, $5 \mathrm{~cm}$ distal to the left ventricular assist device outflow graft. They were immediately able to achieve flows $>3 \mathrm{~L} / \mathrm{min}$ with equivalent mean arterial pressure in both upper extremities and, by postoperative day 5 , had weaned the patient off all inotropic and vasopressor support. The authors reported neither compromise in anastomotic integrity nor any kinking of the native artery and reported no limitation to flow through the ventricular assist device. Ultrasound interrogation of the graft anastomoses demonstrated no overt stenosis with free passage

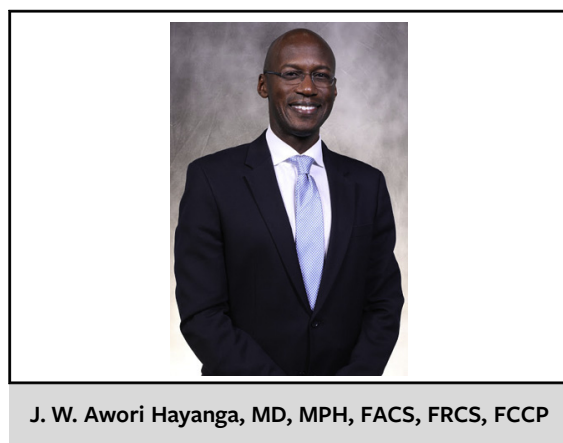

CENTRAL MESSAGE

Extra-anatomic graft to augment flow.

through the intercostal space. The authors thus offer a new and fresh look at flow augmentation with options for extra-anatomic conduits. This interest and the further development of alternative access will undoubtedly fuel demand for the evaluation of comparative outcomes to measure 1 access against another. Should these results, albeit short-term, be the harbinger of what the future holds, then transsternal access could theoretically become an alternative access itself.

\section{References}

1. El-Sayed Ahmed MM, Aftab M, Singh SK, Mallidi HR, Frazier OH Left ventricular assist device outflow graft: alternative sites. Ann Cardiothorac Surg. 2014;3:541-5.

2. Tucker DL, Perry J, Bock A, Douglas A, Albert C, Kirksey L, et al. Left ventricular assist device implantation with axillary-axillary outflow graft. J Thorac Cardiovasc Surg Tech. 2020;4:197-9.
From the Department of Cardiovascular and Thoracic Surgery, West Virginia University, Morgantown, WV.

Disclosures: The authors reported no conflicts of interest.

The Journal policy requires editors and reviewers to disclose conflicts of interest and to decline handling or reviewing manuscripts for which they may have a conflict of interest. The editors and reviewers of this article have no conflicts of interest.

Received for publication Aug 21, 2020; revisions received Aug 21, 2020; accepted for publication Aug 21, 2020; available ahead of print Sept 15, 2020.

Address for reprints: J. W. Awori Hayanga, MD, MPH, FACS, FRCS, FCCP, Department of Cardiovascular and Thoracic Surgery, West Virginia University, 1 Medical Center Dr, Morgantown, WV 26506 (E-mail: jhayanga@me.com).

JTCVS Techniques 2020;4:204

2666-2507

Copyright (C) 2020 The Authors. Published by Elsevier Inc. on behalf of The American Association for Thoracic Surgery. This is an open access article under the CC BY-NCND license (http://creativecommons.org/licenses/by-nc-nd/4.0/).

https://doi.org/10.1016/j.xjtc.2020.08.063 